\title{
Influence of Abrasives in Roller Burnishing Process on Microhardness Using Factorial Design
}

\author{
Pavana Kumara $^{1, *}$, G. K. Purohit ${ }^{2}$ \\ ${ }^{1}$ Department of Mechanical Engineering, Shri Madhwa Vadiraja Institute of Technology \& Management, Bantakal, Udupi, India \\ ${ }^{2}$ Department of Mechanical Engineering, Poojya Doddappa Appa College of Engineering, Aiewan-E-shahi, Gulbarga, India
}

\section{Email address:}

pavansmvitm@gmail.com (P. Kumara),geekey_purohit@rediffmail.com (G. K. Purohit)

${ }^{*}$ Corresponding author

\section{To cite this article:}

Pavana Kumara, G. K. Purohit. Influence of Abrasives in Roller Burnishing Process on Microhardness Using Factorial Design. American Journal of Mechanical and Industrial Engineering. Vol. 2, No. 2, 2017, pp. 111-116. doi: 10.11648/j.ajmie.20170202.18

Received: October 20,2016; Accepted: November 28, 2016; Published: February 16, 2017

\begin{abstract}
Burnishing is essentially a cold-working process used to improve properties of the machined surfaces. In present work, an attempt is made to investigate the effect of fine silicon carbide abrasive particles (in the form of a paste) in between roller burnishing tool and cylindrical components of EN2 4 steel. The mathematical models were developed using $2^{4}$ full factorial design of experiments (DoE) for micro hardness in terms of four variables namely burnishing force, burnishing speed, feed and a number of passes for dry burnishing case and 'with-paste' (where burnishing is done using paste) burnishing case. Analysis of variance (ANOVA) is carried out to check the adequacy of the derived models. The results showed that micro hardness of the untreated EN24 steel can be improved by $11 \%$ and $18 \%$ for dry burnishing case and 'with-paste' burnishing case respectively compared to turned components.
\end{abstract}

Keywords: Machining, Burnishing, Abrasives, Microhardness, Design of Experiments (DoE)

\section{Introduction}

The functional performance of a particular engineering material depends on characteristics at the surface like surface hardness and finish. The hardness plays a vital role in deciding wear rate, impact strength and fatigue life. In general, the traditional method of heat treatment is adopted to increase the hardness of ferrous materials like EN24 grade steel. On other hand, a chipless and forming process like burnishing noticeably enhances the hardness. During the process irregularities present on machined surface deformed plastically using a hard roller. When roller burnishing tool slides over the pre-machined surfaces, which inherently contains peaks and valleys, peaks fills into valleys due to which properties at surface improves.

Previously published works [1-7] presented the results of ball burnishing process on many non-ferrous materials in order to test the influence of numerous parameters and to find the optimised level of parameter combinations on responses. In conclusion, responses like surface roughness, microhardness, wear resistance, ultimate tensile strength, fatigue resistance properties are found to be increased in all the works. The ball burnishing was carried out on $36 \mathrm{Cr} \mathrm{Ni}$ Mo 6 steel using diamond ball [8]. High strength low alloy (HSLA) steels hardness improved to $55-60 \%$ by ball burnishing process using $16.5 \mathrm{~mm}$ diameter ball in presence of grease lubricant [9]. It is also evident that ball burnishing when applied on AISI 1010 steel plates the ductility increased by $49 \%$ [10]. An attempt in made to compare the effects ball and roller burnishing processes on brass and aluminium components [11]. It is interesting to note that ball burnishing produced better hardness, even the force was set at a higher level during roller burnishing.

A study on roller burnishing used RSM with central composite design in finding the effect of speed, feed, force and number of passes on surface roughens, microhardness and residual stresses in St-37 steel [12]. The experiments were conducted in lubricated condition. It has been observed that the speed of the range 150-230 rpm, the force of $35 \mathrm{Kg}$ and a higher number of passes are capable of giving better hardness at the surface. The process is carried on three carbon steels along with aluminium and brass [13]. The results showed that depth of penetration and time are important parameters that contribute to micro hardness. 
The above literature study reveals that both ball and roller burnishing processes are not carried out in presence abrasive paste in between tool and workpiece materials. Hence in this work, an attempt is made to use the silicon carbide abrasive particles in form of paste applied to the workpieces before carrying out roller burnishing process and the effect of using paste is compared with dry burnishing results to conclude the effect of using abrasive materials.

\section{Materials and Equipment}

\subsection{Workpiece Material}

In current work EN24, grade steel was chosen as workpiece material because of its extensive use in the industry. The workpiece is brought in the form of a cylindrical rod of $\phi 20 \mathrm{~mm}$. The workpieces were cut in an appropriate length of 1 feet and turned to $\phi 17 \mathrm{~mm}$ at specific parameter levels. Then numbers of regions were made in turned workpieces at a distance of $25 \mathrm{~mm}$ forming a groove. The turning process was carried in dry condition and the workpieces are used in as brought (raw) condition without heat treating them. The chemical composition of the workpiece is given in table 1 .

Table 1. Chemical composition of the workpiece (by Wt.\%).

\begin{tabular}{llllllll}
\hline $\mathbf{C}$ & $\mathbf{S i}$ & $\mathbf{M n}$ & $\mathbf{P}$ & $\mathbf{C r}$ & $\mathbf{N i}$ & $\mathbf{M o}$ & $\mathbf{C u}$ \\
\hline 0.409 & 0.208 & 0.479 & 0.017 & 0.95 & 1.45 & 0.209 & 0.167 \\
\hline
\end{tabular}

\subsection{Burnishing Tool}

A custom designed and fabricated Roller burnishing tool shown in Figure 1 is used on the conventional lathe for burnishing. A ball bearing is used as Roller, having Outer diameter $=26 \mathrm{~mm}$, Inner diameter $=10 \mathrm{~mm}$ and $\mathrm{Width}=8 \mathrm{~mm}$. The roller (10) can be replaced by removing the key (9). The lower body (1) supports all the inner parts. The locking plate (2) is used to hold the shaft in position. Spring holder (3) and nut (4) are provided to support the other end of the shaft. Spring (5) measures the deflection of the roller against the workpiece surface, thus helps in applying required amount of force. Upper body (6) is provided with required threads to get assembled with the lower body. Roller holder $(7,8)$ shaft is an element that holds the roller and it is inserted in the upper and lower body assembly in presence of force. The stiffness of the spring used in the tool was $1.66 \mathrm{~N} / \mathrm{mm}$ and this is correlated with force while changing the parameter force during experimentation.

UNITECH MTT 636 all geared lathe available at SMVITM, Bantakal laboratory was selected to carry out burnishing experiments. 'With-paste' burnishing is accomplished with Silicon carbide paste as fine abrasives applied on workpieces. Vickers hardness testing machine was used to measure the hardness of the burnished components.
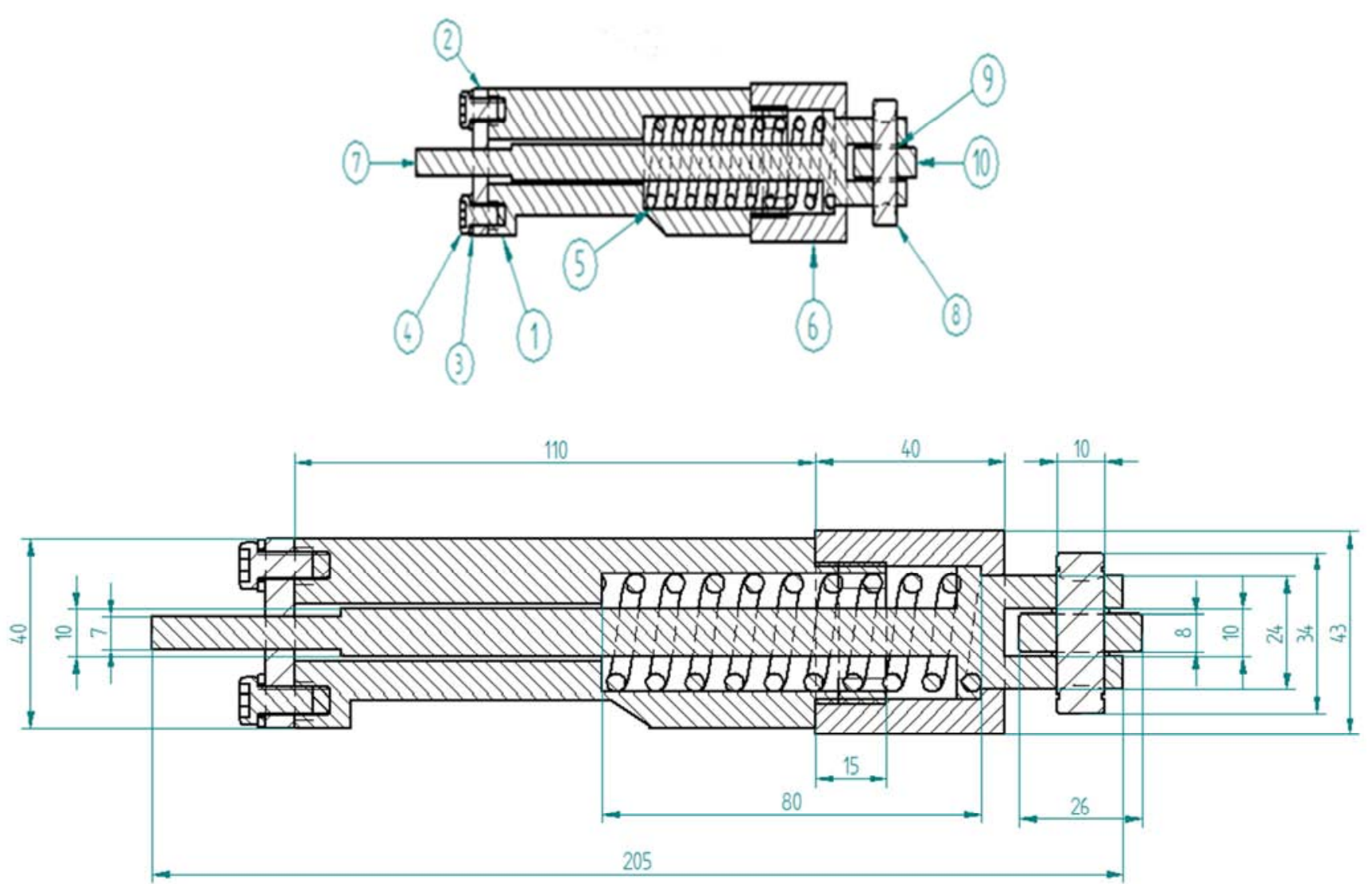

1. Lower body 2. Locking plate 3. Spring washer 4. Nut 5. Spring 6. Upper body 7. Roller holder with tool shaft 8. Roller shaft 9. Key 10. Roller

Figure 1. Burnishing Tool. 


\section{Experimental Work}

The experiments were conducted on all geared lathe based on $2^{4}$ factorial design experimental runs. Experimental set up is shown in figure 2. As it was proposed to compare the results of dry burnishing and 'with-paste' burnishing, a separate set of experiments were carried out for each of the cases. First, the turning was done on workpieces and dry burnishing experiments are carried out on 16 regions. The coded values for the burnishing parameters are given the table 2. Using same levels of parameters next set of 16 experiments were carried out on abrasive paste applied to EN24 workpieces. During the latter case, the kerosene is applied for on workpieces to avoid more heat generation. The abrasive paste is applied by using non-sticking cloth on the workpieces. The uniformity is maintained throughout the surface while applying the paste manually. The advantage of using lathe machine is parameters can be changed easily during experimentation.

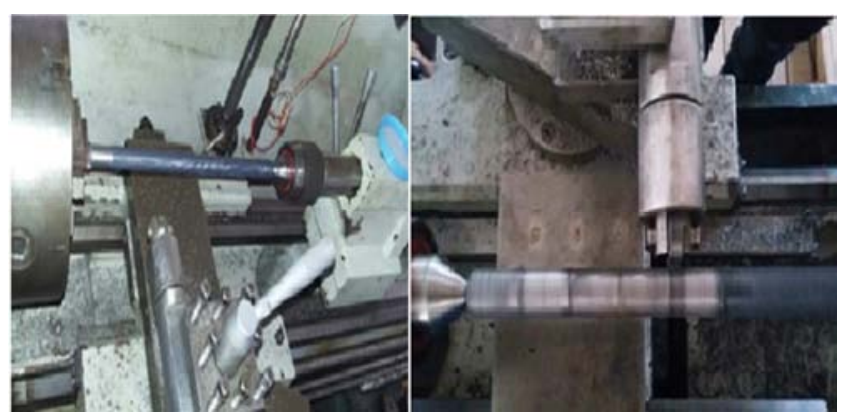

Figure 2. Burnishing operation.

Table 2. Levels of parameter and their coded form.

\begin{tabular}{lllll}
\hline \multirow{2}{*}{ Parameters } & \multirow{2}{*}{ Symbol } & \multicolumn{2}{l}{ Levels } & \\
\cline { 3 - 5 } & & $\mathbf{- 1}$ & $\mathbf{0}$ & $\mathbf{+ 1}$ \\
\hline Force, Kgf (A) & F & 15 & 25 & 35 \\
Speed, rpm (B) & Sp & 165 & 330 & 770 \\
Feed, mm/rev (C) & Fe & 0.049 & 0.08 & 0.1 \\
Number of passes (D) & NOP & 1 & 2 & 3 \\
\hline
\end{tabular}

\section{Design of Experiments}

The experiments in present investigations are planned based on $2^{4}$ full factorial designs of experiments proposed by Box and Hunter [14]. Factorial design provides more flexibility than the conventional method of research, where the single parameter is varied once while other parameters are kept constant. The advantage of such technique is all the combination can be varied in every experimental run. The linear regression model for the micro hardness, $\mathrm{Hv}$ can be given in the following form,

$$
\begin{gathered}
Y=\beta_{0}+\beta_{1} X_{1}+\beta_{2} X_{2}+\beta_{3} X_{3}+\beta_{4} X_{4}+\beta_{12} X_{1} X_{2}+\beta_{13} X_{1} X_{3}+\beta_{23} X_{2} \\
X_{3}+\beta_{24} X_{2} X_{4}+\beta_{123} X_{1} X_{2} X_{3}+\beta_{234} X_{2} X_{3} X_{4}
\end{gathered}
$$

Where, Y represents any response or effect and $\beta 1, \beta 2, \beta 3$, $\beta 123$ and $\beta 124$ represents the regression coefficient to be evaluated by running experiments. X1, X2, X3 and X4 are main effects and they represent the factors force, speed, feed and number of passes respectively.

ANOVA (analysis of variance) is used to check the adequacy of the models. The results of the two set of experiments conducted by using roller burnishing tool i.e. dry and 'with-paste' are presented in table 3.

\section{Results and Discussions}

The results of the experimental runs are tabulated in table 3. The microhardness values for dry and 'with-paste' cases shown that there is a general improvement in microhardens level observed with the workpieces burnished using all the treatment combinations as per design matrix. The microhardness of the initial (turned) workpiece was $236 \mathrm{Hv}$. In general, it was noticed that the application of abrasive paste has been proved advantageous over dry burnishing process.

One of the main objectives of current study is to develop mathematical models for microhardness, Hv for each case and can be given as follows;

Microhardness, Hv (dry) $=227.9+2.550$ F-0.0355 Sp + $313 \mathrm{Fe}+20.78$ NOP- $27.75 \mathrm{~F}^{*} \mathrm{Fe}-1.325 \mathrm{~F}^{*} \mathrm{NOP}+0.157$ $\mathrm{Sp} * \mathrm{Fe}+0.00661 \mathrm{Sp} * \mathrm{NOP}-306 \mathrm{Fe} * \mathrm{NOP}+15.25 \mathrm{~F} * \mathrm{Fe} * \mathrm{NOP}$ $+0.058 \mathrm{Sp}^{*} \mathrm{Fe} * \mathrm{NOP}$

Microhardness, Hv ('with-paste') = 299.4-1.78 F -0.1062 $\mathrm{Sp}-536 \mathrm{Fe}-13.5 \mathrm{NOP}+0.00157 \mathrm{~F}^{*} \mathrm{Sp}+15.5 \mathrm{~F}^{*} \mathrm{Fe}+0.918$ $\mathrm{F}^{* \mathrm{NOP}+} 2.083 \quad \mathrm{Sp} * \mathrm{Fe}-\quad 0.0017 \quad \mathrm{Sp} * \mathrm{NOP}+189$ Fe*NOP-0.0364 F*Sp*F+0.000496 F*Sp*NOP- $\quad 9.50$ $\mathrm{F}^{*} \mathrm{Fe} * \mathrm{NOP}-0.281 \mathrm{Sp}^{*} \mathrm{Fe}^{*} \mathrm{NOP}$

\begin{tabular}{|c|c|c|c|c|c|c|c|c|c|c|}
\hline \multirow{2}{*}{ Run } & \multicolumn{2}{|c|}{ Force, Kgf (F) } & \multicolumn{2}{|c|}{ Speed, rpm (Sp) } & \multicolumn{2}{|c|}{ Feed, mm/rev (Fe) } & \multicolumn{2}{|c|}{ Number of passes (NOP) } & \multirow{2}{*}{$\begin{array}{l}\text { Micro hardness, } \\
\text { Hv for dry case }\end{array}$} & \multirow{2}{*}{$\begin{array}{l}\text { Micro hardness, Hv } \\
\text { in 'with-paste' }\end{array}$} \\
\hline & Level & Value & Level & Value & Level & Value & Level & Value & & \\
\hline 1 & -1 & 15 & -1 & 165 & 1 & 0.098 & -1 & 1 & 250 & 254 \\
\hline 2 & -1 & 15 & -1 & 165 & -1 & 0.049 & -1 & 1 & 254 & 259 \\
\hline 3 & -1 & 15 & 1 & 770 & -1 & 0.049 & -1 & 1 & 245 & 248 \\
\hline 4 & 1 & 35 & 1 & 770 & 1 & 0.098 & -1 & 1 & 245 & 254 \\
\hline 5 & 1 & 35 & -1 & 165 & -1 & 0.049 & 1 & 3 & 239 & 272 \\
\hline 6 & -1 & 15 & 1 & 770 & 1 & 0.098 & -1 & 1 & 241 & 286 \\
\hline 7 & 1 & 35 & 1 & 770 & -1 & 0.049 & 1 & 3 & 245 & 266 \\
\hline 8 & -1 & 15 & -1 & 165 & -1 & 0.049 & 1 & 3 & 255 & 259 \\
\hline 9 & -1 & 15 & -1 & 165 & 1 & 0.098 & 1 & 3 & 239 & 259 \\
\hline 10 & 1 & 35 & -1 & 165 & 1 & 0.098 & 1 & 3 & 245 & 248 \\
\hline 11 & 1 & 35 & -1 & 165 & 1 & 0.098 & -1 & 1 & 245 & 246 \\
\hline
\end{tabular}

Table 3. $2^{4}$ design matrix and results of microhardness, Hv for dry and 'with-paste' roller burnishing case. 


\begin{tabular}{|c|c|c|c|c|c|c|c|c|c|c|}
\hline \multirow{2}{*}{ Run } & \multicolumn{2}{|c|}{ Force, Kgf (F) } & \multicolumn{2}{|c|}{ Speed, rpm (Sp) } & \multicolumn{2}{|c|}{ Feed, mm/rev (Fe) } & \multicolumn{2}{|c|}{ Number of passes (NOP) } & \multirow{2}{*}{$\begin{array}{l}\text { Micro hardness, } \\
\text { Hv for dry case }\end{array}$} & \multirow{2}{*}{$\begin{array}{l}\text { Micro hardness, Hv } \\
\text { in 'with-paste' }\end{array}$} \\
\hline & Level & Value & Level & Value & Level & Value & Level & Value & & \\
\hline 12 & -1 & 15 & 1 & 770 & 1 & 0.098 & 1 & 3 & 248 & 259 \\
\hline 13 & -1 & 15 & 1 & 770 & -1 & 0.049 & 1 & 3 & 250 & 243 \\
\hline 14 & 1 & 35 & 1 & 770 & 1 & 0.098 & 1 & 3 & 257 & 246 \\
\hline 15 & 1 & 35 & 1 & 770 & -1 & 0.049 & -1 & 1 & 255 & 243 \\
\hline 16 & 1 & 35 & -1 & 165 & -1 & 0.049 & -1 & 1 & 268 & 246 \\
\hline
\end{tabular}

\subsection{Main and Interaction Effects of Parameters}

It is clear from figure 3 that only force is having a positive effect on hardness among all parameters in dry burnishing case. This is attributed to the fact that, as force increases the plastic deformation increases at the surface leading to filling the valleys by peaks perfectly. On another hand, when speed, feed and number of passes increases the hardness starts to decrease at the surface. This is due to fact that these parameters are not significant to cause the effective level of deformation at the surface which results in hardness

\section{improvement.}

Whereas the reverse trend is observed in the 'with-paste' case as shown in figure 5 . The force is found to be a parameter which is having an adverse effect on the hardness. The presence of paste causes excessive plastic deformation at the surface at higher forces and causes deterioration of the hardness due to chattering and flaking. The parameters such as speed, feed and number of passes were become effective in presence of paste and tend to fill the irregularities into cavities increasing hardness.

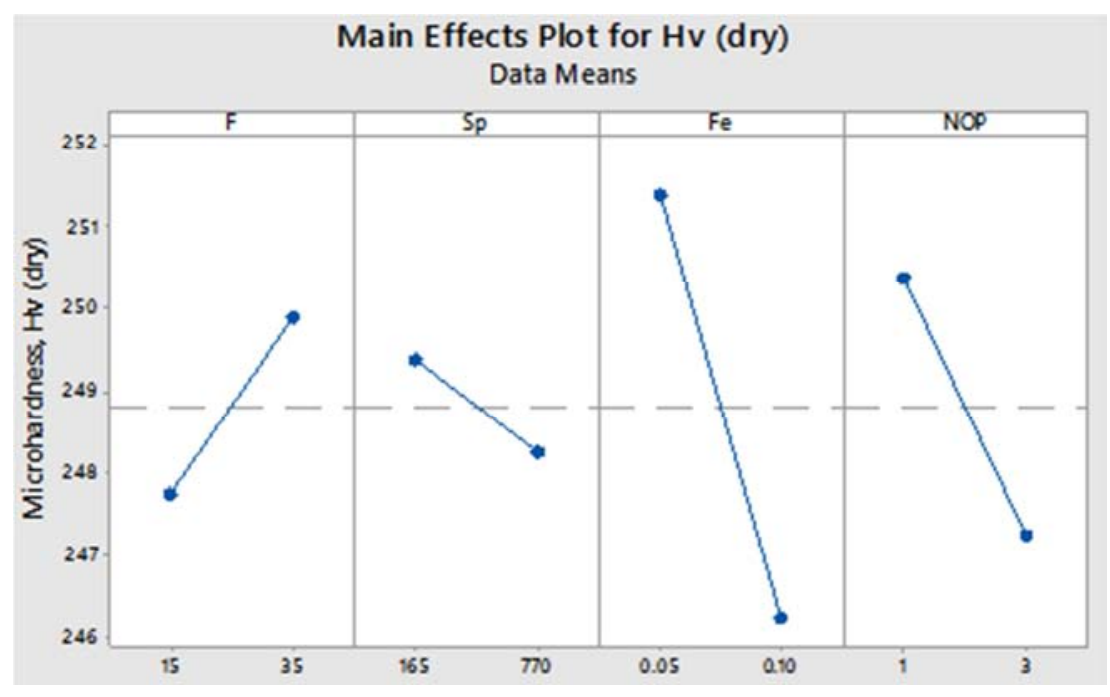

Figure 3. Main effect plot for Hv in dry burnishing.

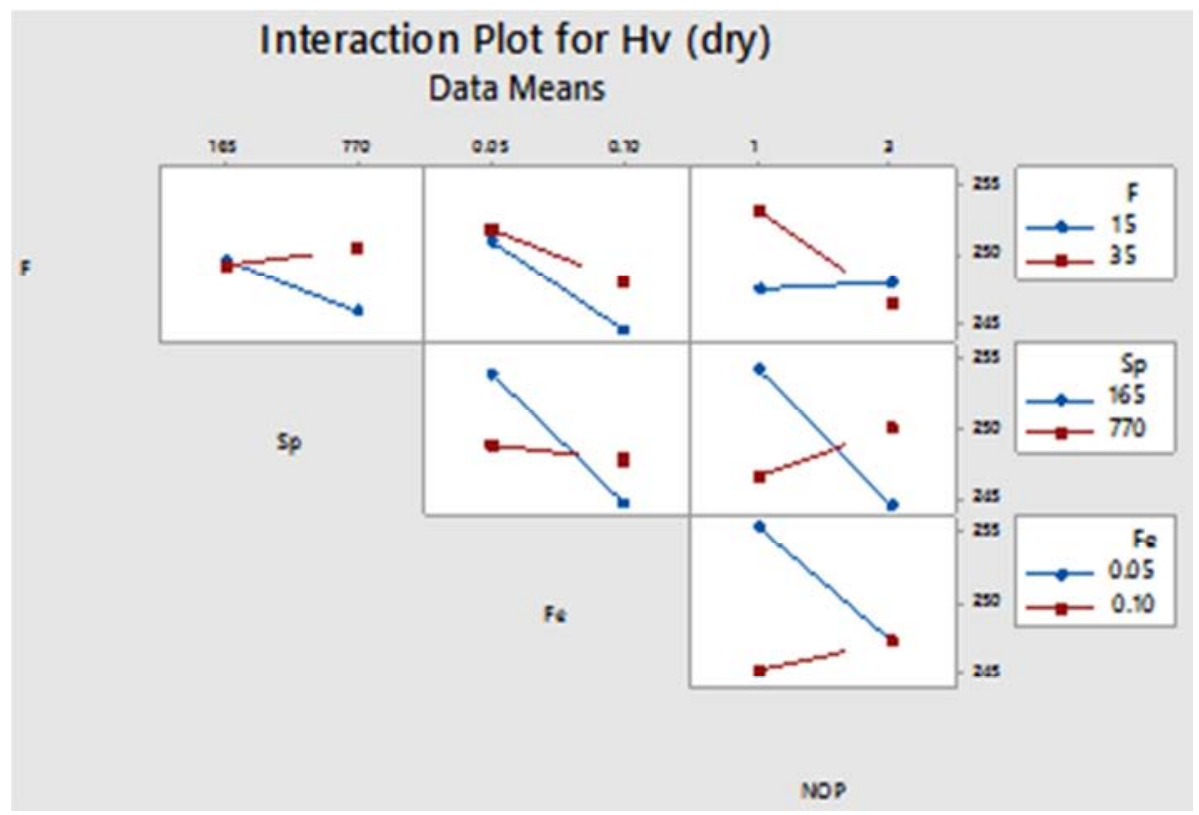

Figure 4. Interaction effects plot for Hv in dry burnishing. 


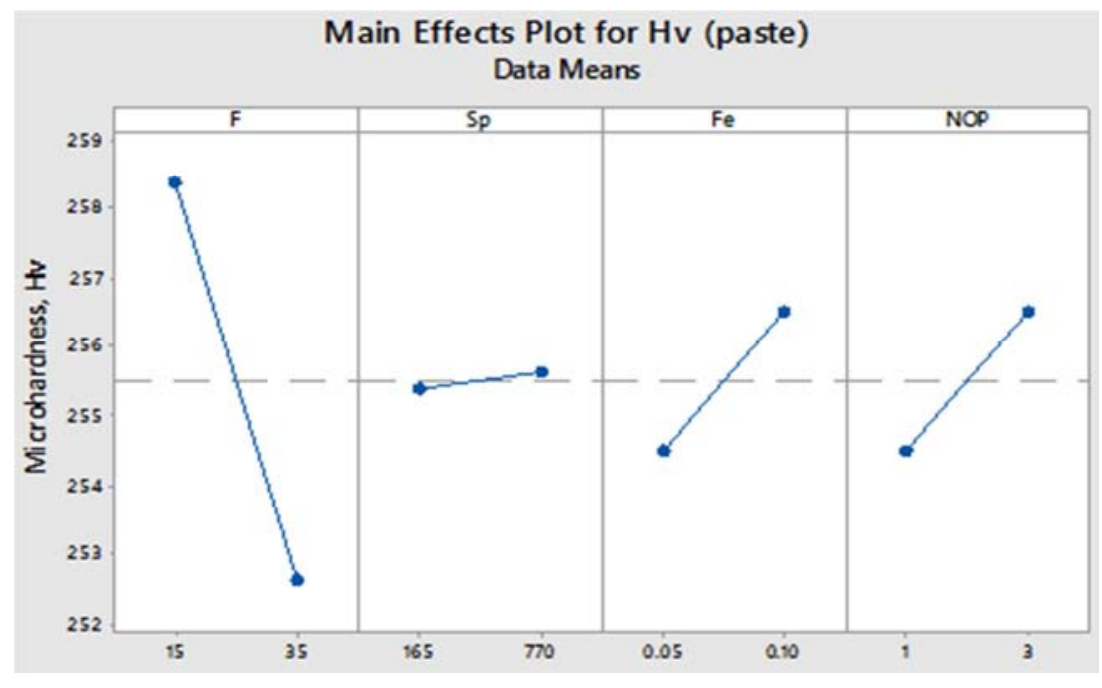

Figure 5. Main effect plot for Hv in 'with-paste' case.

The figures 4 depicts the interaction effects of parameters on microhardness in the case of dry burnishing case. There was a significant effect of interaction effects on the hardness. The combination of a low number of passes and high force will lead to higher hardness due to better deformation capacity of the roller at higher forces. Low feed and lower speed levels cause improvement in hardness which is attributed to more time for deformation of peaks into valleys. The similar effect is observed in the number of passes and speed.

Figure 6 illustrates that there were more prominent interactions between the parameters on microhardness then dry burnishing case except for the interaction between force and speed. It is clear from the figure that at high feed and low force the hardness obtained will be higher than any other cases. it is also evident that lower force at lower number of passes increased hardness. There was seen a great interaction between speed and feed also speed and number of passes. High speed with high feed rate is found to be advantageous in the first case whereas lower speed and higher a number of passes was useful in the latter case. The higher number of passes at lower feed and lower number of passes at high feed are seem to be produced the same level of hardness.

\subsection{Analysis of Variance (ANOVA)}

Analysis of Variance (ANOVA) result is tabulated in tables 4 and 5 respectively for dry and 'with-paste' case. the table 4 shows that in dry burnishing process the main parameter effects are is not significant $(\mathrm{P}$ value is lower than 0.05 ) but the two level and three level interactions will have a significant effect on microhardness and are statistically significant.

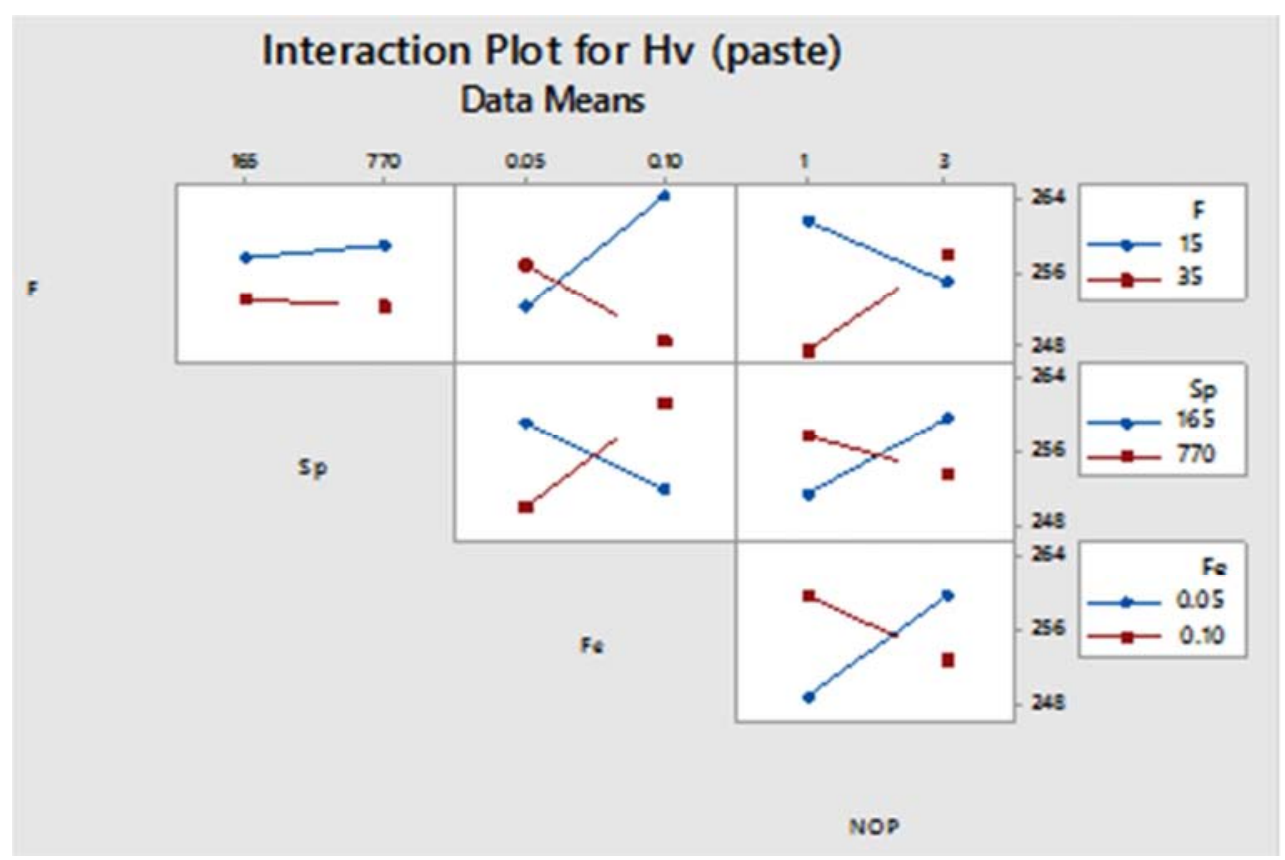

Figure 6. Interaction effects plot for Hv in 'with-paste'case. 
Table 4. ANOVA for dry burnishing case ( $\alpha=0.05 \%)$.

\begin{tabular}{llllll}
\hline Source & DF & Adj.SS & Adj.MS & F-value & P-value \\
\hline Model & 11 & 811.687 & 73.780 & 5.20 & 0.0063 \\
Linear & 4 & 167.250 & 41.812 & 2.95 & 0.160 \\
2-Way Interactions & 5 & 408.812 & 81.762 & 5.76 & 0.0057 \\
3-Way Interactions & 2 & 235.625 & 117.812 & 8.30 & 0.0038 \\
Error & 4 & 56.750 & 14.188 & & \\
Total & 15 & 868.437 & & & \\
\hline
\end{tabular}

S: 3.7666; R-sq: 93.47\%; R-sq(adj): 75.49\%; R-sq(pred): 0.00\%

Table 5. ANOVA for 'with-paste' burnishing case ( $\alpha=0.05 \%)$.

\begin{tabular}{llllll}
\hline Source & DF & Adj.SS & Adj.MS & F-value & P-value \\
\hline Model & 14 & 2037.00 & 145.5 & 5.82 & 0.315 \\
Linear & 4 & 164.50 & 41.125 & 1.64 & 0.521 \\
2-Way Interactions & 6 & 1553. & 258.83 & 10.35 & 0.234 \\
3-Way Interactions & 4 & 319.5 & 79.875 & 3.19 & 0.394 \\
Error & 1 & 25 & 25 & & \\
Total & 15 & 2062.00 & & & \\
\hline
\end{tabular}

S: 5; R-sq: $98.79 \%$; R-sq(adj): $81.81 \%$ R-sq(pred): $0.00 \%$

\section{Conclusion}

The following conclusions can be drawn from the current work;

(1)The burnishing tool developed can be successfully used on conventional, easily available late machine to improve the hardness of the EN24 grade steels

(2)The burnishing process increases the hardness of the workpieces from $236 \mathrm{Hv}$ (initially turned workpiece) to $268 \mathrm{Hv}$ in dry burnishing case and $286 \mathrm{Hv}$ in 'with-paste' burnishing case.

(3)The optimum parameter levels for dry burnishing case were found to be $35 \mathrm{Kgf}$ force, $165 \mathrm{rpm}$ speed, 0.049 $\mathrm{mm} / \mathrm{rev}$ feed and single number of passes

(4)The optimum parameter levels for 'with-paste' burnishing case were found to be $15 \mathrm{Kgf}$ force, $770 \mathrm{rpm}$ speed, $0.098 \mathrm{~mm} / \mathrm{rev}$ feed and single number of passes

(5)There was a greater level of increase in the microhardness is obtained in the 'with-paste' case burnishing proving the use of paste as advantageous.

(6)Without using any other conventional methods to improve the hardness by using this method the hardness can be improved by $13 \%$ and $21 \%$ in dry and 'with-paste' burnishing respectively.

\section{References}

[1] Adel Mahmood Hassan and Aiman Sharef A1-Bsharat, "Influence of burnishing process on surface roughness, hardness and microstructure of some non-ferrous metals", Wear199, 1996, pp 1-8.
[2] Adel Mahmood Hassan and Ayman Mohammad Maqableh, "The effects of initial burnishing parameters on non-ferrous components", Journal of Materials Processing Technology 102, 2000, pp 115-121.

[3] Adel Mahmood Hassan and Aiman Sharef Al- Bsharat, "Improvements in some properties of non-ferrous metals by the application of the ball-burnishing process", Journal of Materials Processing Technology 59, 1996, pp 250-256.

[4] Adel Mahmood Hassan and Sulieman Z. S. Al-Dhifi, "Improvement in the wear resistance of brass Components by the ball burnishing process", Journal of Materials Processing Technology 96, 1999, pp 73-80.

[5] A. M. Hassan, H. F. Al-Jalil and A. A. Ebied, "Burnishing force and number of ball passes for the optimum surface finish of brass component", Journal of Materials Processing Technology 83, 1998, pp 176-179

[6] Dabeer P. S. and Purohit G. K., "Effect of ball burnishing parameters on surface roughness using surface response methodology", Advances in Production Engineering \& Management, 5 Vol 2, 2010, pp 111-116.

[7] M. Fattouh, M. H. El-Axir, and S. M. Serage, "Investigations into the burnishing of external cylindrical surfaces of 70/30 $\mathrm{Cu}-Z n$ alloy”, Wear, 127, 1988, pp 123-131.

[8] Hamid Hamadache, Zahia Zemouri, Lakhdar Laouar and Serge Dominiak, "Improvement of surface conditions of 36CrNiMo6 steel by ball burnishing process", Journal of Mechanical Science and Technology 28 (4), 2014, pp 1491-1498.

[9] D. S. Rao, H. S. Hebbar, M. Komaraiah and U. N. Kempaiah, "Studies on the effect of ball burnishing parameters on surface hardness of HSLA dual-phase steels using factorial design", Trans. Indian Inst. Met., Vol. 61, Nos. 2-3, 2008, pp 187-191.

[10] F. Gharbi, S. Sghaier, F. Morel and T. Benameur, 'Experimental investigation of the effect of burnishing force on service properties of AISI 1010 steel plates", JMEPEG 24 , 2015, pp 721-725.

[11] Adel Mahmood Hassan, "The effects of ball and roller-burnishing on the surface roughness and hardness of some non-ferrous metals", Journal of Materials Processing Technology 72, 1997, pp 385-391.

[12] M. H. El-Axir, "An investigation into roller burnishing", International Journal of Machine Tools \& Manufacture 40, 2000, pp 1603-1617.

[13] M. H. El-Axir and M. M. El-Khabeery, "Influence of orthogonal burnishing parameters on surface characteristics for various materials", Journal of Materials Processing Technology 132, 2003, pp 82-89.

[14] G. E. P. Box, J. S. Hunter, 1957, Multifactor experimental design, Ann. Math. Stat. 28, 195. 